\title{
Results of Sleeve Gastrectomy in Germany-Data on Nationwide Survey on Quality Assurance in Bariatric Surgery in Germany
}

\author{
Christine Stroh $^{1,2^{*}}$, Rudolf Weiner ${ }^{3}$, Thomas Horbach ${ }^{4,5}$, Kaja Ludwig $^{6}$, Miriam Dressler ${ }^{7}$, \\ Stefanie Wolff ${ }^{8}$, Hans Lippert ${ }^{2,8}$, Martin Büsing ${ }^{9}$, Uwe Schmidt ${ }^{10}$, Thomas Manger ${ }^{1,2}$ \\ ${ }^{1}$ Department of General, Abdominal and Pediatric Surgery, Municipal Hospital, Gera, Germany \\ ${ }^{2}$ Institut of Quality Assurance in Surgery gGmbH, University Magdeburg, Magdeburg, Germany \\ ${ }^{3}$ Hospital Sachsenhausen, Frankfurt am Main, Frankfurt Main, Germany \\ ${ }^{4}$ Friedrich Alexander University Erlangen-Nürnberg, Erlangen, Germany \\ ${ }^{5}$ Muncipial Hospital Schwabach, Schwabach, Germany \\ ${ }^{6}$ Hospital Rostock Südstadt, Rostock, Germany \\ ${ }^{7}$ Muncipial Hospitals Dresden Neustadt, Dresden, Germany \\ ${ }^{8}$ Department of General, Abdominal and Vascular Surgery, University Hospital, Magdeburg, Germany \\ ${ }^{9}$ Hospital Knappschaft Recklinghausen, Recklinghausen, Germany \\ ${ }^{10}$ StatConsult Magdeburg, Magdeburg, Germany \\ Email: *Christine.Stroh@wkg.srh.de
}

Received October 28, 2011; revised December 11, 2011; accepted January 20, 2012

\begin{abstract}
Background: Since January $1^{\text {st }}$ of 2005 , the situation of bariatric surgery is being analyzed in Germany. The data is registered prospectively in cooperation with the Institute of Quality Assurance in Surgery at the Otto-von-Guericke University Magdeburg. Methods: The data is registered through an online database which includes all information for primary and revision bariatric procedures as well as yearly follow-up. Participation in the quality assurance study is optional. All certificated centers have to participate at the survey. Results: From January 2006 to December 2009, 1478 sleeve gastrectomies (SG) were performed at 45 hospitals. The number of procedures has increased from 126 in 2007 to 933 in 2009. The main complication is leakage of the staple-line. Initial leakage rate was $7 \%$ in 2007. Leakage rate dropped down to $2.3 \%$ in 2008 and $2.5 \%$ in 2009. Mean age of patients was 43.1 years and mean BMI was $52.83 \mathrm{~kg} / \mathrm{m}^{2}$. Age and BMI were significantly higher in patients with SG than in all other patients undergoing bariatric surgery. Conclusion: SG is a common and hype bariatric procedure in Germany, but postoperative complication rate is high. Data on the long-term effect of SG on weight loss and amelioration of comorbidities need to be evaluated. More detailed analyzes are necessary to establish the position of SG in the bariatric surgery. Further studies should also include examinations on long-term complications and redo-procedure after SG.
\end{abstract}

Keywords: Bariatric Surgery; Sleeve Gastrectomy; German Multicenter Trial; Leakage; Complications

\section{Introduction}

In international comparison, Germany belongs to the countries with a high prevalence of obesity. Depending on age, overweight and obesity affect $25 \%$ to $70 \%$ of the population. The average body mass index (BMI) of the German population in 2009 was $25.7 \mathrm{~kg} / \mathrm{m}^{2}$, with $60.1 \%$ of men and $42.9 \%$ of women overweight [1].

Life expectancy is markedly shortened by obesity, in particular in young obese persons. The mortality risk rises to between six- and 12 -fold of that of the normal population, with a 12-year reduction in life expectancy for overweight men and 9-year reduction for women.

"Corresponding author.
Mortality risk increases 6 to 12 times compared to normal population. For grade III obesity a 20 -year statistically corroborated reduction in life expectancy has been identified [2].

The results of the Swedish Obesity Subject Study (SOS study), which demonstrated the long-term effects of weight reduction on resolution of comorbidities, attest to the marked superiority of surgical treatment measures [3].

In terms of a bariatric treatment concept, sleeve gastrectomy (SG) has been the sole technique practiced since 2000. To date there are no long-term data on weight reduction or on regression of comorbidities. Complica- 
tion rate is considerably influenced by leakage of the staple line. Aim of these study is the comparison of the data on Nationwide Survey on bariatric surgery for SG in Germany with literature.

\section{Methods}

Data of primary bariatric procedures as well as revisional surgery has been evaluated since January $1^{\text {st }}$ of 2005 using Nationwide Survey on quality assurance in bariatric surgery in Germany. Aim of Nationwide Survey is to improve quality on obesity surgery in Germany. Data registration is performed prospectively using an online database [4]. Participation on the Nationwide Survey is voluntary, but all certificated centers of bariatric surgery in Germany have to contribute at the survey. Survey was announced several times since 2005. Participation on the Nationwide Survey is open for all hospitals without any regulations of government or health insurance system. According this conditions number of participating hospitals has been increased from 66 (2005) to 114 in 2009. Patient's selection for bariatric surgery is based on guidelines of IFSO and German Guidelines on Bariatric Surgery [5]. In 2009943 patient's data on SG were retrieved form 45 hospitals. The current report evaluates data of 1 478 patients operated on SG from 2005-2009. Demographic and operative parameters as well as complication and mortality rate after SG were analyzed. The follow-up is collected by follow-up examinations, yearly. Weight loss and changes in comorbidities are gathered.

Data quality of German Nationwide survey is proven by experienced surgeons, control of plausibility and during certification of centers by the auditor as a site visit.

Review on literature was performed on PubMed and Cochrane Database using the keywords sleeve gastrictomy, leakage, staple line insufficiency, mortality and morbidity.

\section{Results}

1478 patients operated on SG has been analyzed using German Nationwide database on Quality assurance in Bariatric Surgery. Since 2005 number of bariatric procedures has been increased, beside the restrictions on health insurance system according obesity and bariatric surgery. In 2005 and 2006 RYGBP and GB were the most performed bariatric procedures in Germany. After introduction of SG in 2006 SG has been the hype procedure with 943 SG performed in 2009. Figure 1 shows the distribution and changes of the different bariatric procedures form 2005 to 2009 (Figure 1).

\subsection{Demographic Data}

$61.7 \%$ of patients with SG were female. Mean age of patients undergoing SG was 43.2 years and mean BMI $52.8 \mathrm{~kg} / \mathrm{m}^{2}$. In comparison with all patients undergoing bariatric surgery in Germany age (41.0 vs. 43.2 years) and BMI (47.9 vs. $52.8 \mathrm{~kg} / \mathrm{m}^{2}$ ) were significant higher in patients with SG $(\mathrm{p}<0.001)$.

\subsection{Comorbidities}

Comorbidities have been evaluated for all patients. At German Nationwide Database $71.6 \%$ of all patients suffer on comorbidities. Patients undergoing SG have significant more comorbidities (90.8\%; p < 0.001). Distribution on comorbidities is shown in Table 1.

\subsection{Operation Data}

Since 2005 we evaluated 1478 at German Nationwide Database at 45 hospitals. Hospital volume ranges between 1 to 146 procedures per year.

For calibration of the stomach, in 2007 mean bougie size was 32.7 (range 22 - 40 Charr) Charriere and in 200935.3 (range 20 - 50 Charr). In 2009, 95.5\% of SG procedures were performed laparoscopically and 3.4\% in open approach. Conversion rate was $1.1 \%$ in 2009. Mean operation time was 96.2 minutes (range 26 - 394) with an intraoperative complication rate of $2.4 \%$. Operative data are shown in Table 2.

\subsection{General and Specific Postoperative Complications}

The frequency of general complications such as pneumonia, urinary infection or cardiac complications, pulmonary embolism and fever was in 2007 14.1\% and decreased to $7.9 \%$ in 2008 and $7 \%$ in 2009.

Specific complications are leakage of the staple line, intraabdominal abscess, bleeding and wound infection

Table 1. Distribution of comorbidities.

\begin{tabular}{lccc}
\hline \multicolumn{1}{c}{ Years } & $\begin{array}{c}2005-2009 \\
\text { all patients }\end{array}$ & $\begin{array}{c}\text { 2005-2009 } \\
\text { patients with SG }\end{array}$ & Significance \\
\hline Comorbidities & {$[\%]$} & {$[\%]$} & \\
Without comorbidities & 18.4 & 9.2 & $<0.001$ \\
Hypertension & 54.3 & 70.1 & $<0.001$ \\
Cardiac comorbidities & 8.4 & 15.0 & $<0.001$ \\
IDDM & 9.2 & 12.7 & $<0.001$ \\
NIDDM & 17.4 & 22.4 & $<0.001$ \\
Respiratory comorbidities & 16.6 & 21.6 & $<0.001$ \\
Sleep apnoea & 16.8 & 25.8 & $<0.001$ \\
Gall stones & 5.3 & 5.8 & 0.386 \\
GERD & 15.5 & 13.5 & 0.051 \\
Varicosis & 5.5 & 9.3 & $<0.001$ \\
Skeletal disease & 41.5 & 52.1 & $<0.001$ \\
\hline
\end{tabular}




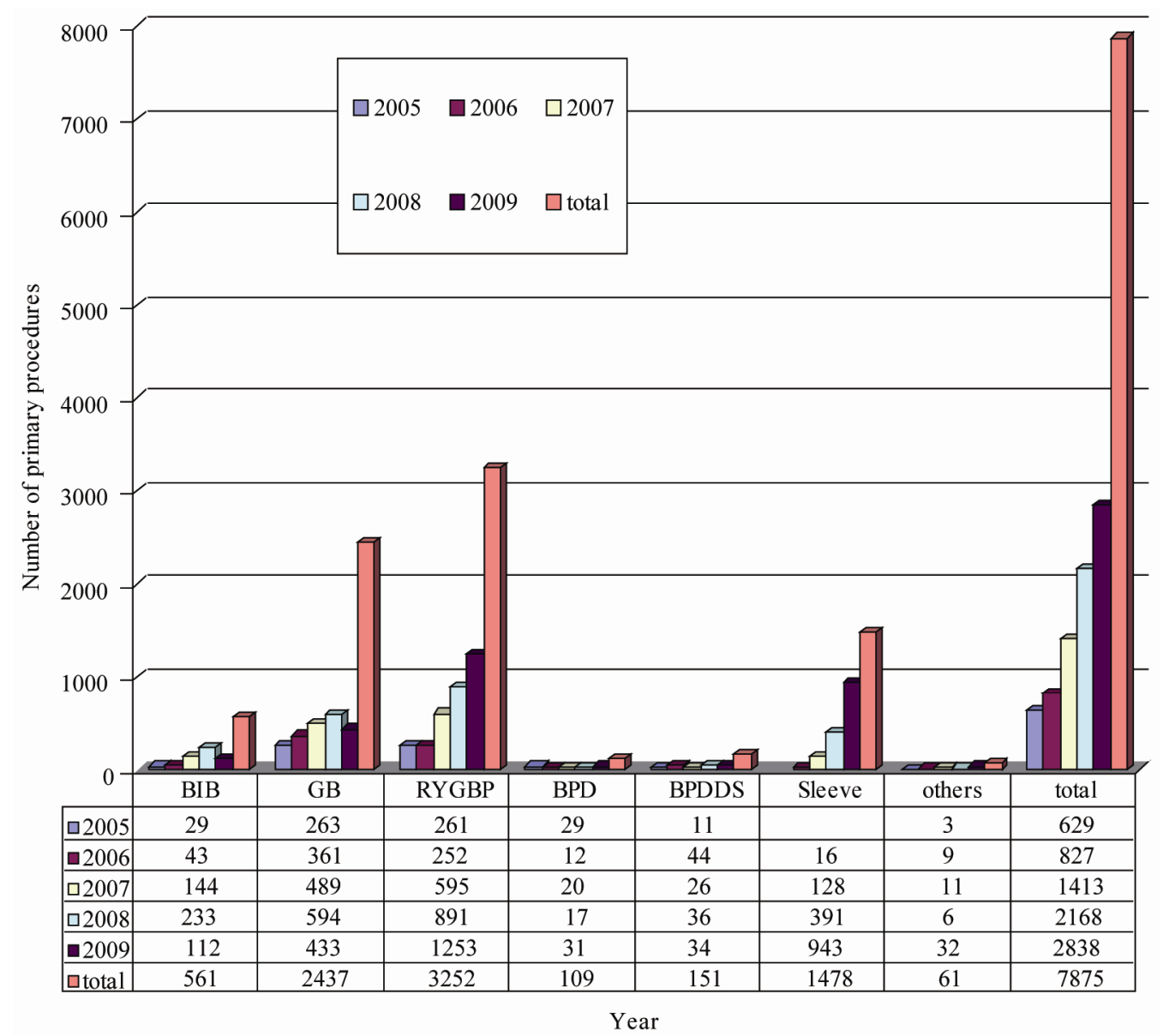

Figure 1. Distribution on primary bariatric procedures in Germany 2005-2009.

Table 2. Operation data.

\begin{tabular}{lcccc}
\hline \multicolumn{1}{c}{ Year } & & 2007 & 2008 & 2009 \\
\hline Number of operations & {$[\mathrm{n}]$} & 126 & 388 & 933 \\
Number of hospitals & {$[\mathrm{n}]$} & 17 & 36 & 45 \\
Hospital volume & {$[\mathrm{n}]$} & $1-67$ & $1-108$ & $1-146$ \\
Mean operative time & {$[\mathrm{min}]$} & 93.1 & 46.1 & 96.2 \\
Laparoscopy & {$[\%]$} & 97.6 & 96.1 & 95.5 \\
Open approach & {$[\%]$} & 2.4 & 2.1 & 3.4 \\
Conversion rate & {$[\%]$} & 0 & 1.8 & 1.1 \\
Mean sleeve volume & {$[\mathrm{ml}]$} & 99.3 & 103.2 & 108.8 \\
Mean bougie size & {$[\mathrm{Charr}]$} & 32.7 & 34.4 & 35.3 \\
Mean resected volume & {$[\mathrm{ml}]$} & 851.4 & 894.8 & 981.2 \\
Staple line butresses & {$[\%]$} & 42.6 & 51.3 & 41.9 \\
Oversewing & {$[\%]$} & 51.1 & 31.2 & 46.9 \\
Without butresses or oversewing & {$[\%]$} & $6, .3$ & 22.2 & 11.2 \\
\hline
\end{tabular}

occurred in 9.4\% in 2007 and 5.1\% in 2008 and 2009. In particular, the leakage rate of the staple-line dropped from $7.1 \%$ in 2007 to $2.3 \%$ in 2008 and $2.5 \%$ in 2009 . The frequency of specific complications is listed in Ta- ble 3.

\subsection{Mortality Rate}

From January $1^{\text {st }}$ of 2006 until December $31^{\text {st }}$ of 2009, 9 patients died after primary SG, the overall mortality after SG is therefore $0.6 \% .8$ of the patients died during the first 30 days and one patient at 72 day due to severe pulmonary infection. Mean BMI of these 6 men and 3 women was $56.5 \mathrm{~kg} / \mathrm{m}^{2}$. All of them suffered on comorbidities of metabolic syndrome (hypertension ( $\mathrm{n}=8 \mathrm{pa}-$ tients); diabetes mellitus ( $\mathrm{n}=4$ patients); sleep apnea ( $\mathrm{n}$ $=6$ patients)).

Table 3. Postoperative complications after SG.

\begin{tabular}{cccccc}
\hline & $\begin{array}{c}\text { Number of } \\
\text { operations }\end{array}$ & Bleeding & $\begin{array}{c}\text { Leckage of } \\
\text { staple line }\end{array}$ & $\begin{array}{c}\text { Stenose } \\
\text { Sleeve }\end{array}$ & $\begin{array}{c}\text { Bowel } \\
\text { obstruction }\end{array}$ \\
\hline Year & {$[\mathrm{n}]$} & {$[\%]$} & {$[\%]$} & {$[\%]$} & {$[\%]$} \\
$2006-2007$ & 144 & 1.6 & 7.0 & 0.8 & 0 \\
2008 & 391 & 2.1 & 2.3 & 0 & 0 \\
2009 & 933 & 1.8 & 2.5 & 0.1 & 0.1 \\
\hline
\end{tabular}




\subsection{Weight Reduction}

For 477 patients, follow-up dates are available 18 months after SG and for 71 patients over 30 months. The detected demographic data shows no difference between surgery- and follow-up. The results of the BMI reduction and weight loss are listed in Table 4.

\section{Discussion}

Data of primary bariatric procedures as well as revisional surgery is gathered since January $1^{\text {st }}$ of 2005 through the Nationwide Survey on quality assurance in bariatric surgery in Germany in order to improve care quality [4]. Number of patients undergoing SG is higher in the Nationwide Survey than in BOLD registry published be DeMaria 2010 [6].

After SG reduction of morbidity and mortality is still in discussion, especially due to the risk of leakage of staple line. Most discussed facts, influencing leakage rate are bougie size, resection of the antrum, using staple line reinforcement or oversewing of the staple line [7]. Leakage and subsequent fistulas near the staple-line especially at the gastro-esophageal junction are the main complications after SG [8-10]. The leakage rate is indicated at 0 to $5.5 \%[10,11]$. The effect of bougie size on the leakage rate has not been examined using randomized controlled studies, but bougie size influences the leakage rate $[7,11]$. Some authors recommend overstitching the staple-line [9]. Literature has shown a decreased bleeding risk using staple line buttresses $[13,14]$. A protective effect from staple-line reinforcement to the advantage of leakage reduction could not be shown in randomized controlled studies. However, shorter surgery times and less blood loss have been described with its use.

In the study, the overall postoperative complication rate after SG is $14.1 \%$ (2007), $7.9 \%$ (2008) and $7.0 \%$ (2009). Leakage rate at the staple line was reduced from $7.0 \%$ (2007) to 2.5\% (2009). Report on BOLD registry does not discuss complication rate after SG. Only data on complication rate of the BOLD registry in totally has been published until now [6].

Literature shows an overall complication rate of up to $24 \%$ with a median mortality rate of $0.37 \%[12,15]$. In the quality assurance study the mortality rate is $0.6 \%$. Major issue of this procedure is the possibility of surgical complications due to insufficiency/leakage of the stapler line with or without fistulas. Such insufficiency accounts for morbidity (up to 80\%) and mortality. Even though there are many approaches to resolving the stapler insufficiency (including reinforcement of the stapler with several foreign materials), it is an ongoing issue and might be one of the serious downsides of SG.

Influence of the higher BMI and age of patients undergoing SG in Germany on leakage rate, morbidity and mortality has to investigate further on. Cohorts with more than 5000 patients are necessary to evaluate these facts from the statistical point of view.

The quality assurance trial insures a detailed data-collection as it is describe at the methods. Latest recommendations for leakage rate reduction are on the one hand associated with the lack of mobilization of the periesophageal fat with the aim to preserve a minimum of one centimeter of stomach-wall lateral of the Hiss angle and the avoidance of stenosis in the area of the angulus fold on the other hand [16].

Table 5 reflects current data from literature on staplerline insufficiency rates, perioperative morbidity and mortality in comparison with data from the quality assurance study (Table 5).

A systematic literature research shows an overweight reduction after SG of $33 \%$ to $85 \%$ [17]. Studies have proven a correlation between bougie size and the extent of weight loss [15,18].

Patients with a BMI $>60 \mathrm{~kg} / \mathrm{m}^{2}$ profit from SG in the bariatric therapy concept as long as this procedure is chosen as the initial surgery [19]. It is however, gaining value as a single procedure [20,21]. Long-term results of follow-up data of more than 5 years are only available in few studies [18,23,24].

\section{Conclusions}

According to literature and data on German Nationwide Survey the following operative technical details should be registered and evaluated in further studies such as through detailed data collection in the quality assurance study:

- Diameter of the calibration tube;

- Use of staple-line reinforcement;

- Use of the stapler with the fewest leakage rate;

Table 4. Reduction of BMI.

\begin{tabular}{|c|c|c|c|c|c|}
\hline \multirow[b]{2}{*}{$\mathrm{OP}$} & \multirow{3}{*}{$\begin{array}{c}\text { Months after operation } \\
\text { [months] }\end{array}$} & \multirow{3}{*}{$\begin{array}{l}\text { Number of patients } \\
\qquad[\mathrm{n}]\end{array}$} & \multicolumn{3}{|c|}{ BMI } \\
\hline & & & OP & Follow up & BMI-Reduction \\
\hline & & & {$\left[\mathrm{kg} / \mathrm{m}^{2}\right]$} & {$\left[\mathrm{kg} / \mathrm{m}^{2}\right]$} & {$\left[\mathrm{kg} / \mathrm{m}^{2}\right]$} \\
\hline \multirow[t]{3}{*}{ SG } & $0-6$ & 105 & 55.6 & 47.9 & -7.7 \\
\hline & $6-18$ & 477 & 53.8 & 39.7 & -14.1 \\
\hline & $18-30$ & 71 & 54.1 & 39.0 & -15.2 \\
\hline
\end{tabular}


Table 5. Complications after SG-Review in literature.

\begin{tabular}{|c|c|c|c|c|c|c|c|}
\hline Author & Year & Number of patients & Follow up & BMI & Bougie & Overall complication rate & Mortality \\
\hline & & [n] & [mo] & {$\left[\mathrm{kg} / \mathrm{m}^{2}\right]$} & [Charr] & [\%] & \\
\hline Regan [25] & 2003 & 7 & 11 & 63 & 60 & 42.8 & 0 \\
\hline Almogy [26] & 2004 & 21 & 18 & 57.5 & & 23.8 & 0 \\
\hline Baltazar [15] & 2005 & 31 & 27 & $35-74$ & 32 & 6.7 & $1 / 31$ \\
\hline Langer [27] & 2005 & 10 & 6 & 43.3 & & 0 & 0 \\
\hline Milone [28] & 2005 & 20 & 6 & 69 & 60 & 5 & \\
\hline Mognol [29] & 2005 & 10 & 12 & 64 & & 0 & 0 \\
\hline Moon [30] & 2005 & 130 & 12 & 37.2 & 48 & 2.9 & $1 / 130$ \\
\hline Cottam [31] & 2006 & 126 & 12 & 65.4 & $46-50$ & 13 & \\
\hline Himpens [20] & 2006 & 40 & 36 & 39 & 34 & 5 & 0 \\
\hline Hamoui [32] & 2006 & 118 & 24 & 55 & & 15.3 & $1 / 118$ \\
\hline Langer [33] & 2006 & 23 & 18 & 48.5 & & & \\
\hline Roa [34] & 2006 & 30 & 6 & 41.2 & 52 & 13.3 & \\
\hline Silecchia [35] & 2006 & 41 & 12 & 57.3 & 48 & 12.1 & 0 \\
\hline Braghetto [36] & 2007 & 50 & 12 & 37.9 & $32-40$ & 2 & 0 \\
\hline Dapri [37] & 2007 & 40 & 12 & 42.5 & 32 & 2.5 & 0 \\
\hline Givon-Madhala [38] & 2007 & 25 & 4 & 44 & & & \\
\hline Lalor [11] & 2007 & 164 & 29 & 42 & 44 & & 0 \\
\hline Lee [39] & 2007 & 216 & 24 & 49 & 32 & 7.4 & 0 \\
\hline Melissas [40] & 2007 & 23 & 12 & 47.2 & 34 & 21.7 & 0 \\
\hline Serra [9] & 2007 & 993 & & $35-51$ & & 9.4 & $<1$ \\
\hline Tucker [41] & 2007 & 148 & 3 & 45.9 & 36 & 7.4 & 0 \\
\hline Weiner [19] & 2007 & 120 & & & $32-44$ & 17.5 & $1 / 120$ \\
\hline Parikh [42] & 2008 & 120 & 12 & 60.1 & $40-60$ & & 0 \\
\hline Felberhauer [43] & 2008 & 126 & 19 & 48.1 & 48 & 3.2 & 0 \\
\hline Rubin [44] & 2008 & 120 & 11 & 43.5 & 48 & 0 & 0 \\
\hline Srekas [45] & 2008 & 93 & 12 & 48.9 & 36 & 4.3 & 0 \\
\hline Mui [46] & 2008 & 70 & 12 & 40.7 & 38 & 2.9 & 0 \\
\hline Gagner [47] & 2008 & 63 & 12 & 68 & & 6.3 & 0 \\
\hline Kasalicky [48] & 2008 & 61 & 18 & 41.8 & 38 & 3.2 & 0 \\
\hline Frezza [49] & 2008 & 53 & 18 & 53.5 & $29-38$ & 9.4 & 0 \\
\hline Uglioni [50] & 2009 & 41 & 36 & 46.3 & 35 & 9.8 & 0 \\
\hline Fuks [51] & 2009 & 135 & 12 & 48.8 & & 5.1 & 0 \\
\hline Stroh [22] & 2009 & 144 & 24 & 54.5 & 32 & 14.1 & 2 \\
\hline Himpens [24] & 2010 & 41 & 72 & 39.9 & & 12.2 & \\
\hline German Survey 2006-2009 & & 1478 & 36 & 52.8 & 32.7 & 7.5 & 9/1478 \\
\hline
\end{tabular}


- Influence on comorbidities on leakage rate;

- Influence on gender on leakage rat.

The aim is to define the importance of SG in the bariatric therapy concept by gathering a high number of patients and a detailed data collection through the quality assurance trial [22].

\section{Conflict of Interests}

The German Nationwide Survey is supported by: Johnson \& Johnson MEDICAL GmbH, Ethicon Endo-Surgery Germany, Norderstedt; Covidien Germany GmbH, Neustadt/Donau; Lamed GmbH, Oberhaching/München, Germany; Pharm-Allergan GmbH, Ettlingen, Germany; Sanofi-Aventis Germany GmbH, Berlin; W. L. Gore Associaties GmbH, Putzbrunn, Germany.

A conflict of interests or any connection to products mentioned in this report does not exist.

\section{Acknowledgements}

We thanks the following hospitals for participation: Hospital Augsburg; DRK Hospital Berlin Köpenick; MIC Hospital Berlin; Hospital Herzogin-Elisabeth-Heim Braunschweig; Muncipial Hospital Dresden Neustadt; Hospital Dinslaken; Dominikus Hospital Düsseldorf; Universitätsklinikum Erlangen; Hospital St. Johann Nepomuk Erfurt; Hospital Friesoythe; Hospital Fulda; Hospital Frankfurt Sachsenhausen; DRK-Hospital Clementinenhaus Hannover; St. Vinzenz-Hopsital Hanau; Hospital Alten Eichen Hamburg; Hospital Ibbenbüren; Muncipial Hospital Karlsruhe; Hospital Köln Merheim; St. Franziskus-Hospital Köln; University Leipzig AöR; St. Franziskus Hospital Lohne; Otto-von-Guericke-University Magdeburg; University Hospital Mannheim; Hospital München Bogenhausen; Herz-Jesu-Hopsital Münster; St. Marien-Hospital Ratingen; Hospital Recklinghausen; Hospital Südstadt Rostock; Muncipial Hospital Schwabach; Hospital Tönning; Hospital Villingen/Schwenningen; University Ulm; Hospital Zweibrücken.

\section{REFERENCES}

[1] Statistisches-Bundesamt. Mikrozensus. 2009 Wiesbaden: Statistisches Bundesamt. Federal Statistical Office. 2010 Microcensus. 2009 Wiesbaden: Federal Statistical Office.

[2] K. R. Fontaine, D. T. Redden, C. Wang, A. O. Westfall and D. B. Allison, "Years of Life Lost Due to Obesity," The Journal of the America Medical Association (JAMA), Vol. 289, No. 2, 2003, pp. 187-193. doi:10.1001/jama.289.2.187

[3] L. Sjöström, K. Narbro, C. D. Sjöström, K. Karason, B. Larsson, H. Wedel, T. Lystig, M. Sullivan, C. Bouchard, B. Bengtsson, S. Dahlgren, A. Gummesson, P. Jacobsen, J. Karlsson, A. K. Lindross, H. Lönroth, I. Naslund, T. Olbers, K. Stenlof, J. Torgerson, J. Agren and L. Carlsson,
"Effects of Bariatric Surgery on Mortality in Swedish Obese Subjects," The New England Journal of Medicine, Vol. 357, No. 8, 2007, pp. 741-752. doi:10.1056/NEJMoa066254

[4] C. Stroh, D. Birk, R. Flade-Kuthe, M. Frenken, B. Herbig, S. Höhne, H. Köhler, K. Ludwig, P. Pick, Th. Horbach, S. Krause, L. Schäfer, R. Weiner, S. Wolff, A. M. Wolf, U. Schmidt and Th. Manger, "Arbeitsgruppe Adipositaschirurgie. Quality Assurance in Bariatric Surgery in Germany-Results of the German Multicentre Trial 2005 and 2006,” Zentralblatt fur Chirurgie, Vol. 133, No. 5, 2008, pp. 473-478. doi:10.1055/s-2008-1077002

[5] M. Fried, V. Hainer, A. Basdevant, H. Buchwald, M. Deitel, N. Finer, J. W. Greve, F. Horber, E. Mathus-Vliegen, N. Scopinaro, R. Steffen, C. Tsigos, R. Weiner, K. Widhalm and Bariatric Scientific Collaborative Group Expert Panel, "Interdisciplinary European Guidelines for Surgery for Severe (Morbid) Obesity,” Obesity Surgery, Vol. 17, Vol. 2, 2007, pp. 260-270.

doi:10.1007/s11695-007-9025-2

[6] E. J. DeMaria, V. Pate, M. Warthen, et al., "Baseline Data from American Society for Metabolic and Bariatric Surgery-Designated Bariatric Surgery Centers of Excellence Using the Bariatric Outcomes Longitudinal Database,” Surgery for Obesity and Related Diseases, Vol. 6, No. 4, 2011, pp. 347-355.

[7] M. Deitel, M. Gagner, A. L. Erickson and R. D. Crosby, "Third International Summit: Current Status of Sleeve Gastrectomy,” Surgery for Obesity and Related Diseases, Vol. 7, No. 6, 2011, pp. 749-759.

[8] C. Serra, A. Baltasar, N. Pérez, R. Bou and M. Bengochea, "Total Gastrectomy for Complications of the Duodenal Switch, with Reversal," Obesity Surgery, Vol. 16, No. 8, 2006, pp. 1082-1086. doi:10.1381/096089206778026271

[9] C. Serra, A. Baltasar, L. Andreo, N. Pérez, R. Bou, M. Bengochea and J. J. Chisbert, "Treatment of Gastric Leaks with Coated Self-Expanding Stents after Sleeve Gastrectomy," Obesity Surgery, Vol. 17, No. 7, 2007, pp. 866872. doi:10.1007/s11695-007-9161-8

[10] S. Agarwal, S. U. Kini and D. M. Herron, "Laparoscopic Sleeve Gastrectomy for Morbid Obesity: A Review," Surgery for Obesity and Related Diseases, Vol. 3, No. 2, 2007, pp. 189-194. doi:10.1016/j.soard.2006.10.013

[11] P. F. Lalor, O. N. Tucker, S. Szomstein and R. J. Rosenthal, "Complications after Laparoscopic Sleeve Gastrectomy," Surgery for Obesity and Related Diseases, Vol. 4, No. 1, 2007, pp. 33-38.

[12] Clinical Issues Committee of American Society for Metabolic and Bariatric Surgery, "Sleeve Gastrectomy as a Bariatric Procedure,” Surgery for Obesity and Related Diseases, Vol. 3, No. 6, 2007, pp. 573-576.

[13] A. Assalia, K. Ueda, R. Matteotti, F. Cuenca-Abente, T. Rogula and M. Gagner, "Staple-Line Reinforcement with Bovine Pericardium in Laparoscopic Sleeve Gastrectomy: Experimental Comparative Study in Pigs," Obesity Surgery, Vol. 17, No. 2, 2007, pp. 222-228.

[14] E. C. Consten, M. Gagner, A. Pomp and W. B. Inabnet, "Decreased Bleeding after Laparoscopic Sleeve Gastrectomy with or without Duodenal Switch for Morbid Obe- 
sity Using a Stapled Buttressed Absorbable Polymer Membrane," Obesity Surgery, Vol. 14, No. 10, 2004, pp. 1360-1366. doi:10.1381/0960892042583905

[15] K. M. Stamou, E. Menenakos, D. Dardamanis, C. Arabatzi, L. Alevizos, K. Albanopoulos, E. Leandros and G. Zografos, "Prospective Comparative Study of the Efficacy of Staple-Line Reinforcement in Laparoscopic Sleeve Gastrectomy,” Surgical Endoscopy, Vol. 25, No. 11, 2011, pp. 3526-3520.

[16] A. Baltasar, C. Serra, N. Pérez, R. Bou, M. Bengochea and L. Ferri, "Laparoscopic Sleeve Gastrectomy: A MultiPurpose Bariatric Operation,” Obesity Surgery, Vol. 15, No. 8, 2005, pp. 1124-1128. doi:10.1381/0960892055002248

[17] D. Bellanger and F. L. Greenway, "Laparoscopic Sleeve Gastrectomy, 529 Cases without Leak: Short-Term Results and Technical Considerations,” Obesity Surgery, Vol. 21, No. 2, 2011, pp. 146-150. doi:10.1007/s11695-010-0320-y

[18] S. A. Brethauer, J. P. Hammel and P. R. Schauer, "Systematic Review of Sleeve Gastrectomy as Staging and Primary Bariatric Procedure," Surgery for Obesity and Related Diseases, Vol. 5, No. 4, 2009, pp. 469-475.

[19] R. A. Weiner, S. Weiner, I. Pomhoff, C. Jacobi, W. Makarewicz and G. Weigand, "Laparoscopic Sleeve Gastrectomy-Influence of Sleeve Size and Resected Gastric Volume," Obesity Surgery, Vol. 17, No. 10, 2007, pp. 1297-1305. doi:10.1007/s11695-007-9232-x

[20] M. Gagner and C. Boza, "Laparoscopic Duodenal Switch for Morbid Obesity,” Expert Review of Medical Devices, Vol. 3, No. 1, 2006, pp. 105-112. doi:10.1586/17434440.3.1.105

[21] E. E. Frezza, "Laparoscopic Vertical Sleeve Gastrectomy for Morbid Obesity. The Future Procedure of Choice?” Surgery Today, Vol. 37, No. 4, 2007, pp. 275-281. doi:10.1007/s00595-006-3407-2

[22] C. Stroh, D. Birk, R. Flade-Kuthe, M. Frenken, B. Herbig, S. Höhne, H. Köhler, V. Lange, K. Ludwig, R. Matkowitz, G. Meyer, F. Meyer, P. Pick, T. Horbach, S. Krause, L. Schäfer, M. Schlensak, E. Shang, T. Sonnenberg, M. Susewind, H. Voigt, R. Weiner, S. Wolff, H. Lippert, A. M. Wolf, U. Schmidt, T. Manger and Bariatric Surgery Working Group, “A Nationwide Survey on Bariatric Surgery in Germany-Results 2005-2007,” Obesity Surgery, Vol. 19, No. 1, 2009, pp. 105-112. doi:10.1007/s11695-008-9736-z

[23] J. Himpens, G. Dapri and G. B. Cadière, “A Prospective Randomized Study between Laparoscopic Gastric Banding and Laparoscopic Isolated Sleeve Gastrectomy: Results after 1 and 3 Years,” Obesity Surgery, Vol. 16, No. 11, 2006, pp. 1450-1456. doi:10.1381/096089206778869933

[24] J. Himpens, J. Dobbeleir and G. Peeters, "Long-Term Results of Laparoscopic Sleeve Gastrectomy for Obesity," Annals of Surgery, Vol. 252, No. 2, 2010, pp. 319-314. doi:10.1097/SLA.0b013e3181e90b31

[25] J. P. Regan, W. B. Inabnet, M. Gagner and A. Pomp, "Early Experience with Two-Stage Laparoscopic Rouxen-Y Gastric Bypass as an Alternative in the Super-Super
Obese Patient,” Obesity Surgery, Vol. 13, No. 6, 2003, pp. 861-864. doi:10.1381/096089203322618669

[26] G. Almogy, P. F. Crookes and G. J. Anthone, "Longitudinal Gastrectomy as a Treatment for the High-Risk Super-Obese Patient,” Obesity Surgery, Vol. 14, No. 4, 2004, pp. 492-497. doi:10.1381/096089204323013479

[27] F. B. Langer, M. A. Reza-Hoda, A. Bohdjalian, F. X. Felberbauer, J. Zacherl, E. Wenzl, K. Schindler, A. Luger, B. Ludvik and G. Prager, "Sleeve Gastrectomy and Gastric Banding: Effects on Plasma Ghrelin Levels,” Obesity Surgery, Vol. 15, No. 7, 2005, pp. 1024-1029. doi:10.1381/0960892054621125

[28] L. Milone, V. Strong and M. Gagner, "Laparoscopic Sleeve Gastrectomy Is Superior to Endoscopic Intragastric Balloon as a First Stage Procedure for Super-Obese Patients $(\mathrm{BMI}>$ or $=50)$," Obesity Surgery, Vol. 15, No. 5, 2005, pp. 612-617. doi:10.1381/0960892053923833

[29] P. Mognol, D. Chosidow and J. P. Marmuse, "Laparoscopic Sleeve Gastrectomy (LSG): Review of a New Bariatric Procedure and Initial Results,” Surgical Technology International, Vol. 15, 2006, pp. 47-52.

[30] S. Moon-Han, W. W. Kim and J. H. Oh, "Results of Laparoscopic Sleeve Gastrectomy (LSG) at 1 Year in Morbidly Obese Korean Patients,“ Obesity Surgery, Vol. 15, No. 10, 2005, pp. 1469-1475. doi:10.1381/096089205774859227

[31] D. Cottam, F. G. Qureshi, S. G. Mattar, S. Sharma, S. Holover, G. Bonanomi, R. Ramanathan and P. Schauer, "Laparoscopic Sleeve Gastrectomy as an Initial WeightLoss Procedure for High-Risk Patients with Morbid Obesity,” Surgical Endoscopy, Vol. 20, No. 6, 2006, pp. 859863. doi:10.1007/s00464-005-0134-5

[32] N. Hamoui, G. J. Anthone, H. S. Kaufman and P. F. Crookes, "Sleeve Gastrectomy in the High-Risk Patient," Obesity Surgery, Vol. 16, No. 11, 2006, pp. 1445-1449. doi:10.1381/096089206778870157

[33] F. B. Langer, A. Bohdjalian, F. X. Felberbauer, E. Fleischmann, M. A. Reza-Hoda, B. Ludvik, J. Zacherl, R. Jakesz and G. Prager, "Does Gastric Dilatation Limit the Success of Sleeve Gastrectomy as a Sole Operation for Morbid Obesity?” Obesity Surgery, Vol. 16, No. 2, 2006, pp. 166-171. doi:10.1381/096089206775565276

[34] P. E. Roa, O. Kaidar-Person, D. Pinto, M. Cho, S. Szomstein and R. J. Rosenthal, "Laparoscopic Sleeve Gastrectomy as Treatment for Morbid Obesity: Technique and Short-Term Outcome," Obesity Surgery, Vol. 16, No. 10, 2006, pp. 1323-1326. doi:10.1381/096089206778663869

[35] G. Silecchia, C. Boru, A. Pecchia, M. Rizzello, G. Casella, F. Leonetti and N. Basso, "Effectiveness of Laparoscopic Sleeve Gastrectomy (First Stage of Biliopancreatic Diversion with Duodenal Switch) on Co-Morbidities in Super-Obese High-Risk Patients," Obesity Surgery, Vol. 16, No. 9, 2006, pp. 1138-1144. doi:10.1381/096089206778392275

[36] I. Braghetto, O. Korn, H. Valladares, L. Gutiérrez, A. Csendes, A. Debandi, J. Castillo, A. Rodríguez, A. M. Burgos and L. Brunet, "Laparoscopic Sleeve Gastrectomy: Surgical Technique, Indications and Clinical Results,” Obesity Surgery, Vol. 17, No. 11, 2007, pp. 1442-1450. 


\section{doi:10.1007/s11695-008-9421-2}

[37] G. Dapri, C. Vaz, G. B. Cadière and J. Himpens, “A Prospective Randomized Study Comparing Two Different Techniques for Laparoscopic Sleeve Gastrectomy,” Obesity Surgery, Vol. 17, No. 11, 2007, pp. 1435-1441. doi:10.1007/s11695-008-9420-3

[38] O. Givon-Madhala, R. Spector, N. Wasserberg, N. Beglaibter, H. Lustigman, M. Stein, N. Arar and M. Rubin, "Technical Aspects of Laparoscopic Sleeve Gastrectomy in 25 Morbidly Obese Patients,” Obesity Surgery, Vol. 17, No. 6, 2007, pp. 722-727. doi:10.1007/s11695-007-9133-z

[39] C. M. Lee, P. T. Cirangle and G. H. Jossart, "Vertical Gastrectomy for Morbid Obesity in 216 Patients: Report of Two-Year Results," Surgical Endoscopy, Vol. 21, No. 10, 2007, pp. 1810-1816. doi:10.1007/s00464-007-9276-y

[40] J. Melissas, S. Koukouraki, J. Askoxylakis, M. Stathaki, M. Daskalakis, K. Perisinakis and N. Karkavitsas, "Sleeve Gastrectomy: A Restrictive Procedure?” Obesity Surgery, Vol. 17, No. 1, 2007, pp. 57-62. doi:10.1007/s11695-007-9006-5

[41] O. N. Tucker, S. Szomstein and R. J. Rosenthal, "Indications for Sleeve Gastrectomy as a Primary Procedure for Weight Loss in the Morbidly Obese,” Journal of Gastrointestinal Surgery, Vol. 12, No. 4, 2008, pp. 662-667. doi:10.1007/s11605-008-0480-4

[42] M. Parikh, M. Gagner, L. Heacock, G. Strain, G. Dakin and A. Pomp, "Laparoscopic Sleeve Gastrectomy: Does Bougie Size Affect Mean \%EWL? Short-Term Outcomes," Surgery for Obesity and Related Diseases, Vol. 4, No. 4, 2008, pp. 528-533.

[43] F. X. Felberbauer, F. Langer, S. Shakeri-Manesch, E. Schmaldienst, M. Kees, S. Kriwanek, M. Prager and G. Prager, "Laparoscopic Sleeve Gastrectomy as an Isolated Bariatric Procedure: Intermediate-Term Results from a Large Series in Three Austrian Centers," Obesity Surgery, Vol. 18, No. 7, 2008, pp. 814-818. doi:10.1007/s11695-008-9483-1

[44] M. Rubin, R. T. Yehoshua, M. Stein, D. Lederfein, S.
Fichman, H. Bernstine and L. A. Eidelman, "Laparoscopic Sleeve Gastrectomy with Minimal Morbidity. Early Results in 120 Morbidly Obese Patients,” Obesity Surgery, Vol. 18, No. 12, 2008, pp. 1567-1570. doi:10.1007/s11695-008-9652-2

[45] G. Skrekas, D. Lapatsanis, V. Stafyla and A. Papalambros, "One Year after Laparoscopic 'tight' Sleeve Gastrectomy: Technique and Outcome,” Obesity Surgery, Vol. 18, No. 7, 2008, pp. 810-813. doi:10.1007/s11695-008-9440-Z

[46] W. L. Mui, E. K. Ng, B. Y. Tsung, C. C. Lam and M. Y. Yung, "Laparoscopic Sleeve Gastrectomy in Ethnic Obese Chinese,” Obesity Surgery, Vol. 18, No. 12, 2008, pp. 1571-1574. doi:10.1007/s11695-008-9538-3

[47] M. Gagner, A. A. Gumbs, L. Milone, E. Yung, L. Goldenberg and A. Pomp, "Laparoscopic Sleeve Gastrectomy for the Super-Super-Obese (Body Mass Index >60 $\mathrm{kg} / \mathrm{m}^{2}$ )," Surgery Today, Vol. 38, No. 5, 2008, pp. 399403. doi:10.1007/s00595-007-3645-y

[48] M. Kasalicky, D. Michalsky, J. Housova, M. Haluzik, D. Housa, D. Haluzikova and M. Fried, "Laparoscopic Sleeve Gastrectomy without an Over-Sewing of the Staple Line," Obesity Surgery, Vol. 18, No. 10, 2008, pp. 1257-1262. doi:10.1007/s11695-008-9635-3

[49] E. E. Frezza, S. Reddy, L. L. Gee and M. S. Wachtel, "Complications after Sleeve Gastrectomy for Morbid Obesity," Obesity Surgery, Vol. 19, No. 6, 2009, pp. 684-687. doi:10.1007/s11695-008-9677-6

[50] B. Uglioni, B. Wölnerhanssen and T. Peters, C. ChristoffelCourtin, B. Kern and R. Peterli, "Midterm Results of Primary vs Secondary Laparoscopic Sleeve Gastrectomy (LSG) as an Isolated Operation,” Obesity Surgery, Vol. 19, No. 4, 2009, pp. 401-406. doi:10.1007/s11695-009-9804-Z

[51] D. Fuks, P. Verhaeghe, O. Brehant, C. Sabbagh, F. Dumont, M. Riboulot, R. Delcenserie and J. M. Regimbeau, "Results of Laparoscopic Sleeve Gastrectomy: A Prospective Study in 135 Patients with Morbid Obesity," Surgery, Vol. 145, No. 1, 2009, pp. 106-113. doi:10.1016/j.surg.2008.07.013 